\title{
THE INFLUENCE OF THE STRUCTURE ON THE FATIGUE PROPERTIES OF Al-Mg CAST ALLOY
}

\begin{abstract}
The article will be focused on monitoring the influence of the structure on the fatigue properties of aluminium alloys for the casting of type Al-Mg. As an experimental material were used aluminium alloys EN AC 51200 and EN AC 51500, supplied in a cast state without a heat treatment. They were produced by the continuous casting method. These alloys were selected on the basis of the chemical composition, where the content of most alloying elements is comparable, only in the case of the concentration of magnesium are these alloys significantly different. Fatigue properties of aluminium alloys were tested by three-point bending cyclic loading. The fracture surface of the testing sample was examined using scanning electron microscopy (SEM), where samples were observed on various stages of the fatigue process, their characteristics and differences of fracture surfaces.
\end{abstract}

Keywords: Al-Mg cast alloy, fatigue property, three-point bending loading, fracture surface, structure

\section{Introduction}

Aluminium alloys with magnesium as the major alloying element constitute a group of heat treatable alloys with medium strength, high ductility, excellent corrosion resistance and weldability [1-3]. Wrought Al-Mg alloys are used as structural materials in marine, automotive, aircraft and cryogenic applications while the cast forms are used mainly for their corrosion resistance in dairy, food handling and chemical processing applications. Unlike the heat treatable alloys, these materials derive their strength primarily from solid solution strengthening by $\mathrm{Mg}$, which has a substantial solid solubility in aluminium. However, in order to obtain strength levels approaching the regime of the precipitation hardening alloys, high $\mathrm{Mg}$ levels are required. Such high levels of $\mathrm{Mg}$ pose processing challenges and can increase the susceptibility of the alloys to stress corrosion cracking [3-6].

Fatigue failures in metallic structures are a well-known technical problem. In a specimen subjected to a cyclic load, a fatigue crack nucleus can be initiated on a microscopically small scale, followed by crack grows to a macroscopic size, and finally to specimen failure in the last cycle of the fatigue life. Understanding of the fatigue mechanism is essential for considering various technical conditions which affect fatigue life and fatigue crack growth, such as the material surface quality, residual stress, and environmental influence. This knowledge is essential for the analysis of fatigue properties of an engineering structure [7-9].

\section{Material characteristics}

As an experimental material were used aluminium cast alloys of type Al-Mg (EN AC-51200 and EN AC-51500), supplied in a cast state without a heat treatment in the form of plates (Fig. 1). They were produced by the continuous casting method. Test samples for determining the fatigue properties were made by the cutting operation from these plates, which were cut from casts (Fig. 2). The chemical composition of both alloys was examined by spark emission spectrometer SPECTROMAXx and results are shown in the Table 1. These alloys were selected based on this chemical composition, where the content of most of alloying elements is comparable, only a concentration of magnesium is considerably different.

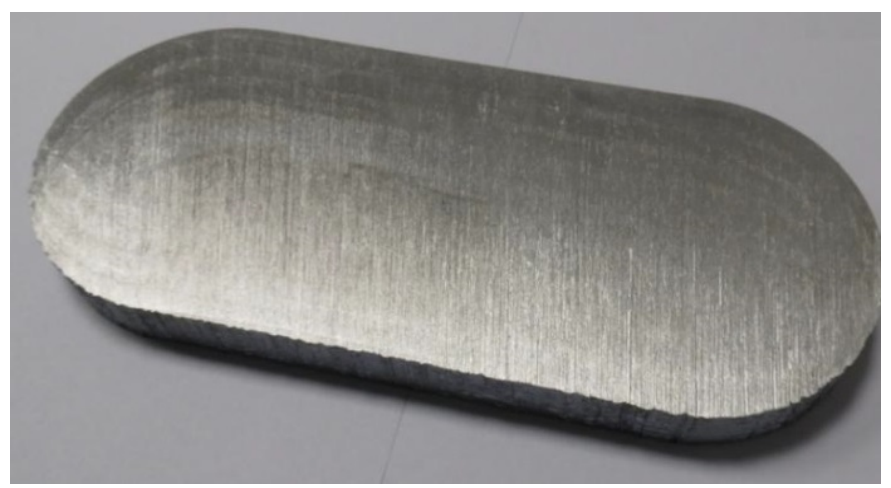

Fig. 1. The plate cut from a casting 


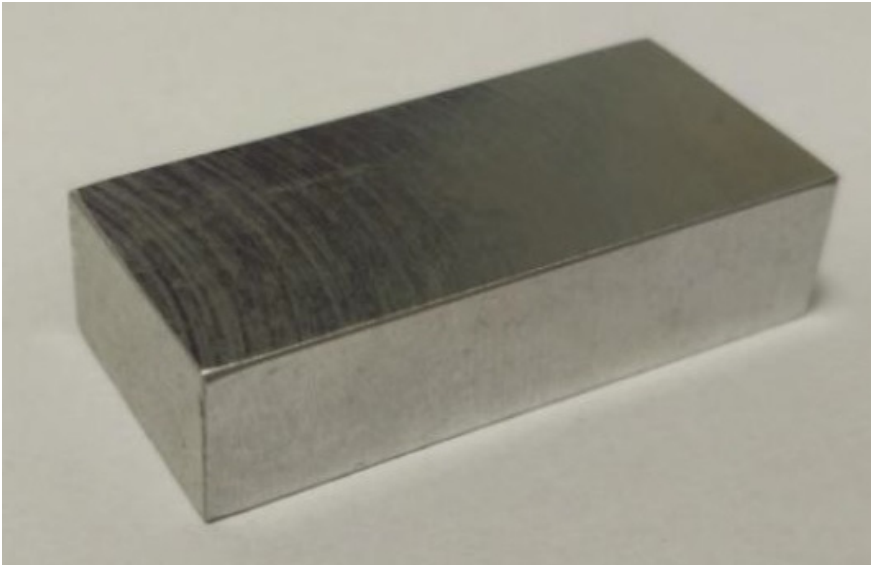

Fig. 2. The sample for a fatigue test

TABLE 1

The chemical composition of alloys, in wt. \%

\begin{tabular}{|c|c|c|c|c|c|c|c|c|}
\hline & Si & Fe & Cu & Mn & Mg & Cr & Pb & Al \\
\hline EN AC 51200 & 1.3 & 0.102 & 0.003 & 0.416 & 10.32 & 0.006 & 0.027 & balance \\
\hline EN AC 51500 & 1.53 & 0.11 & 0.004 & 0.529 & 6.28 & 0.008 & 0.031 & balance \\
\hline
\end{tabular}

These materials have excellent corrosion resistance, very good workability, polishability and good weldability. The advantage of these alloys is that they are used without a heat treatment, thereby saving the costs of production of parts. Products from these alloys are mainly produced by high pressure casting method.

\section{Experiment methodology}

\subsection{Metallographic analysis}

Preparation of samples, which need to be given a very good attention because of its quality depends on the quality of the analysis of structures, consisted of the following operations:
Cutting - Specimens for metallographic analysis were taken from supplied plates, using a precision automatic saw MTH MIKRON 3000. Samples were cutting without damage by deformation or without heat affection.

Preparation - For the sample preparation was used a hot mounting equipment STRUERS CITOPRESS and mixtures Dentacryl and Bakelite. Pressing of samples took about 3 minutes at temperature $180^{\circ} \mathrm{C}$ and pressure $25 \mathrm{MPa}$.

Grinding - After mounting of samples, they were grinded by using a semiautomatic equipment TEGRASYSTEM. For this operation were used two abrasive discs with a various grain size. The rough grinding was done by an abrasive disc with a grain size 500 and for the fine grinding was used an abrasive disc with a gain size 1200. Both grinding was carried out for 1 minute. During this operation, discs were wetted with water to prevent the heat affected of samples.

Polishing - It was also performed on a semiautomatic machine TEGRASYSTEM and it was carried out in three steps. In the first step of polishing, it was used a polishing disc MDMol with a suspension DiaProMol, in the second step was used a disc MDNap with a suspension DiaProNap and in the last step was used a disc MDChem with a paste OP-S.

Etching - Samples were etched with $0.5 \%$ hydrofluoric acid solution for 10 seconds.

The thus prepared samples were used for metallographic analysis, using a light metallographic microscope NEOPHOT 32.

\subsection{Fatigue tests}

Fatigue tests were carried out on the test equipment ZWICK/ROELL AMSLER 150 HFP 5100 (Fig. 3) according to norm STN 42 0363. This equipment is using the resonance principle with constant or variable amplitude and mean load. Smooth rectangular specimens without notches $(10 \times 18 \times 40 \mathrm{~mm})$ (Fig. 2) were loaded by cyclic three-point bending loading with mean stress $\sigma_{m}=-144 \mathrm{MPa}$ and frequency $120 \mathrm{~Hz}$.

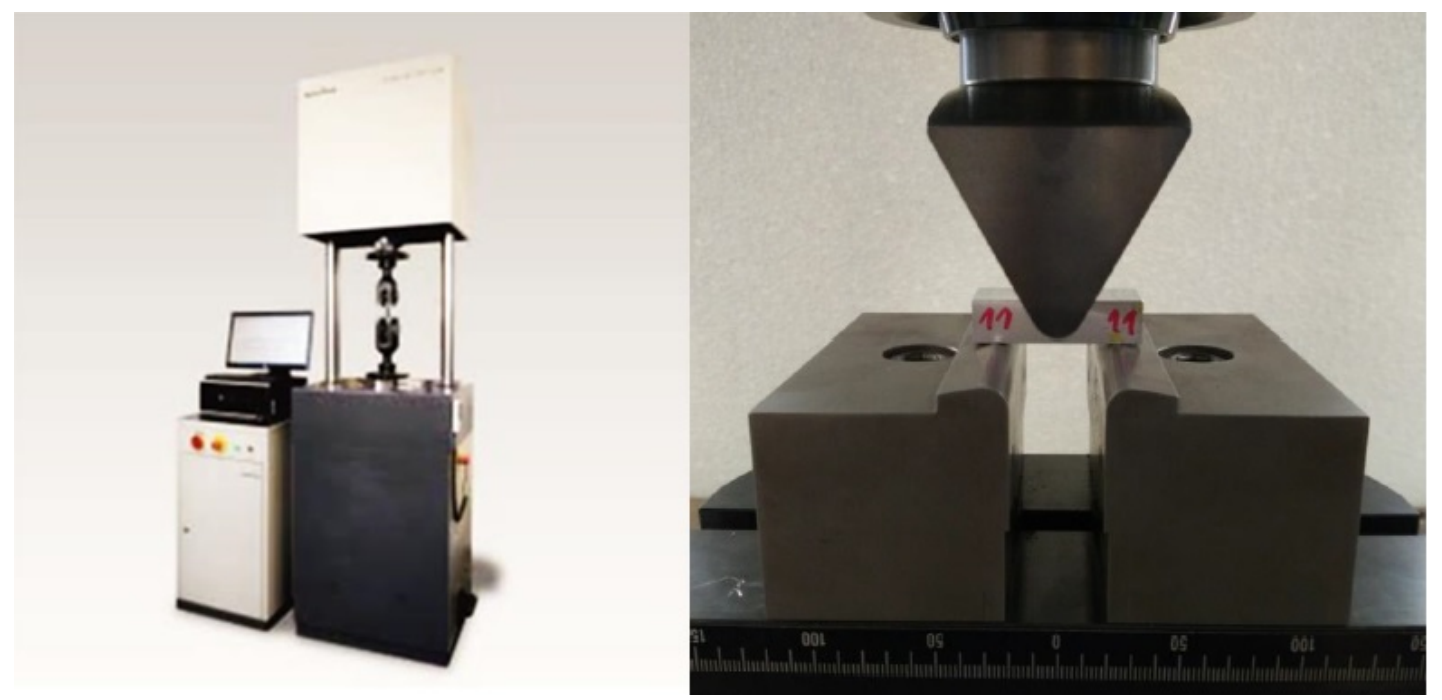

Fig. 3. The test equipment ZWICK/ROELL AMSLER 150 HFP 5100 


\subsection{Fractography}

Fractographical assessment of fracture surfaces was realized on samples from each material after the fatigue test. On samples were observed various stages of fatigue process, their characteristics and differences of fracture surfaces between samples loading in high and low amplitude of stress. It has also been observed an area of final fracture. Fracture surfaces were evaluated by scanning electron microscopy TESCAN VEGA LMU II.

\section{Results and discussion}

\subsection{Microstructural analysis and phase analysis}

Considering that alloys were casted under the same technological conditions, it can be said that the structure affects only the chemical composition of alloys. Microstructure of materi- als is expressively dendritic (Fig. 4). The highest percentage representation of dendrites has $\alpha$-phase (matrix) that is a solid solution of aluminium together with other additive elements. In the structure, there is also an intermetallic phase $\mathrm{Mg}_{2} \mathrm{Si}$. This phase has a different morphology in alloys. In the case of EN AC 51200 alloy, it has a shape of skeleton formation and is distributed in interdendritic areas. There is also $\beta$-phase, which is formed in interdendritic areas and has a stoichiometric basis $\mathrm{Al}_{3} \mathrm{Mg}_{2}$. In alloy EN AC 51500, intermetallic phase $\mathrm{Mg}_{2} \mathrm{Si}$ has a finer morphology and does not have a typical shape of skeleton formation.

Because elements such as iron and manganese are also in alloys, can be observed a small amount of Fe-rich phase in structure of both materials, probably $\mathrm{Al}_{6}(\mathrm{FeMn}) . \beta$-phase is not present in this alloy, because of the smaller content of magnesium.

For identification and confirmation of structural components was used square and line analysis. Results are shown in Figs. 5-8.
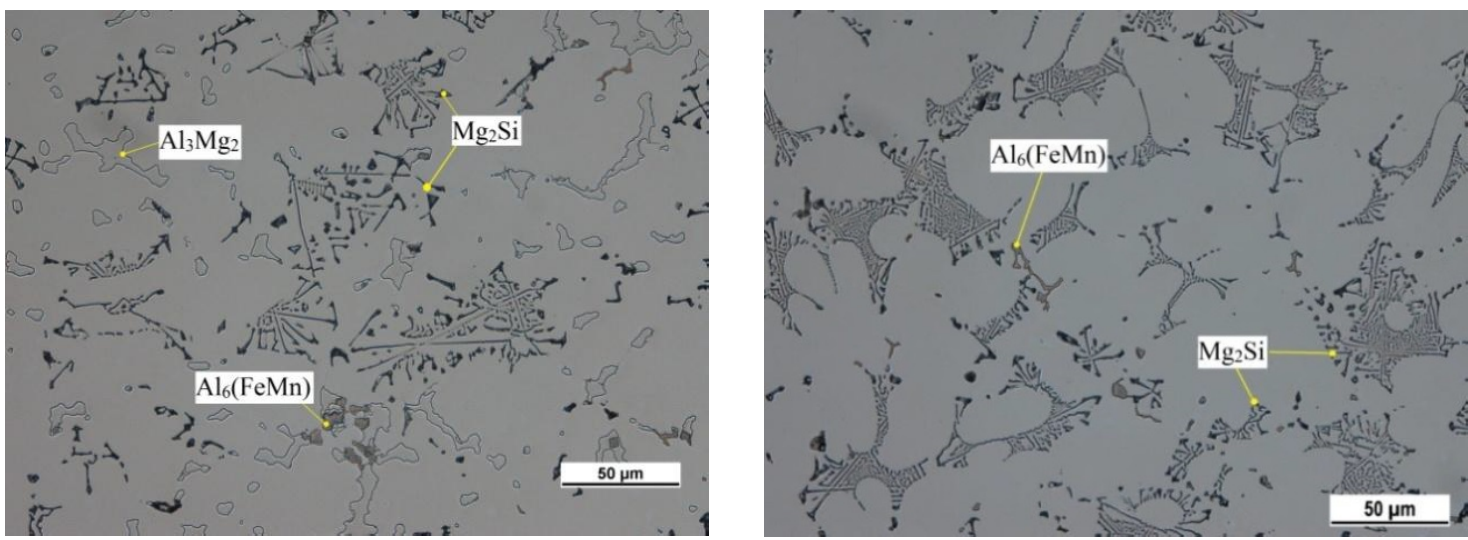

Fig. 4. Microstructures of aluminium alloys
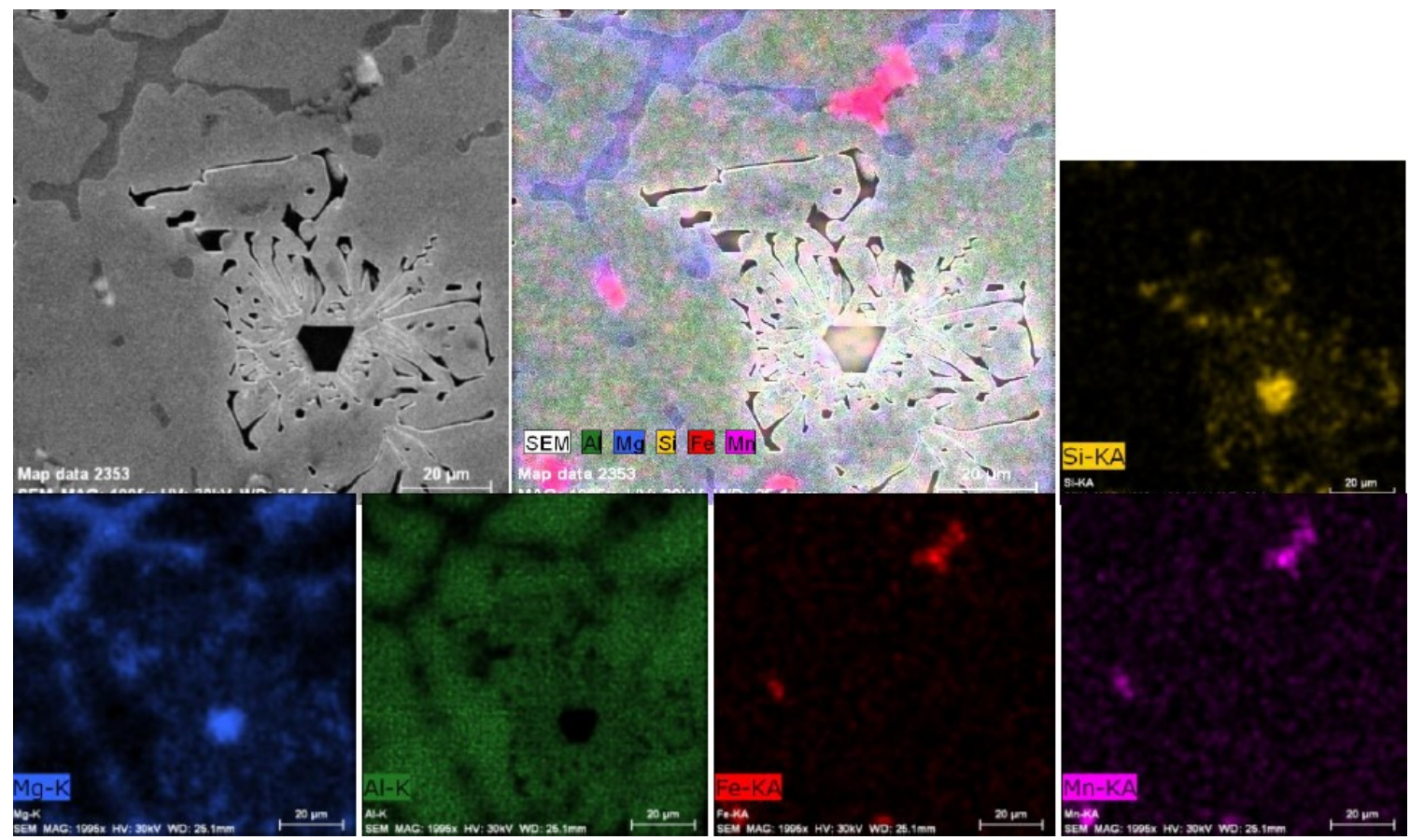

Fig. 5. Identification of structural components of aluminium alloy EN AC 51200 - a square analysis 

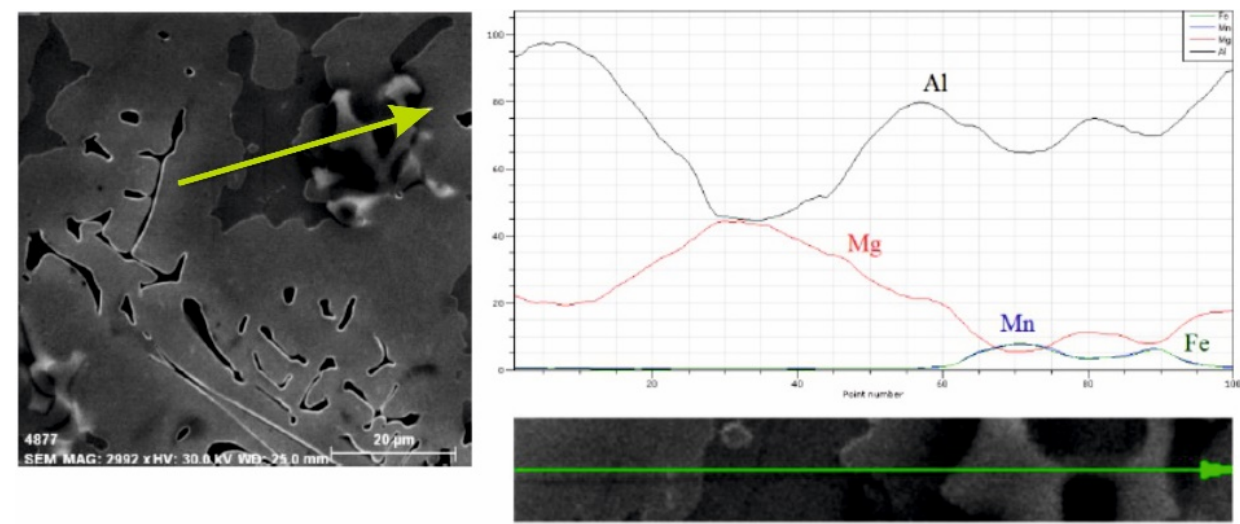

a) $\mathrm{Al}_{6}(\mathrm{FeMn})$ and $\mathrm{Al}_{3} \mathrm{Mg}_{2}$
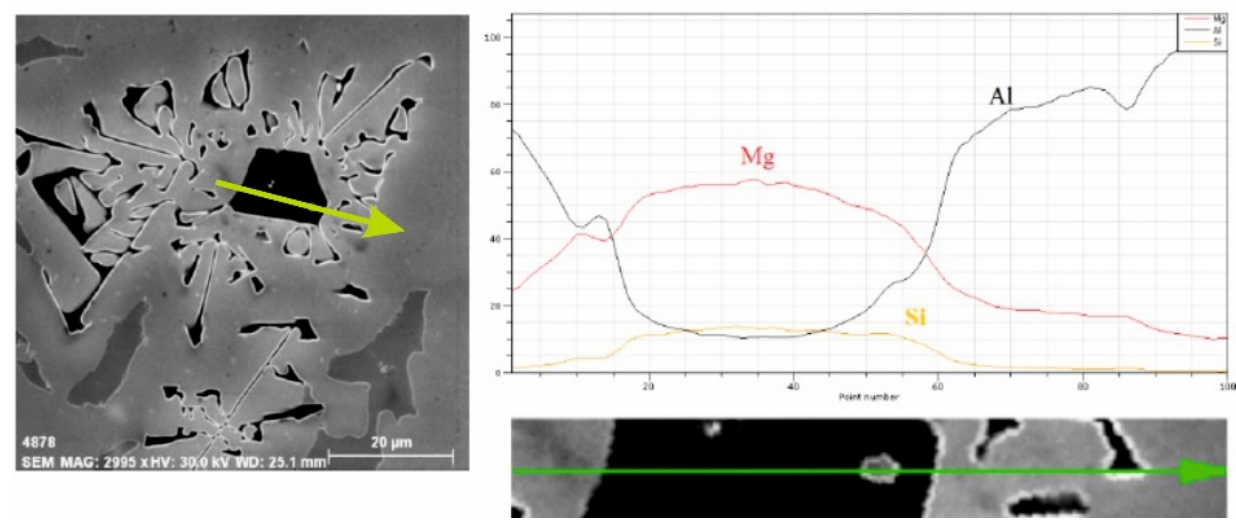

Fig. 6. Identification of structural components of aluminium alloy EN AC 51200 - a line analysis

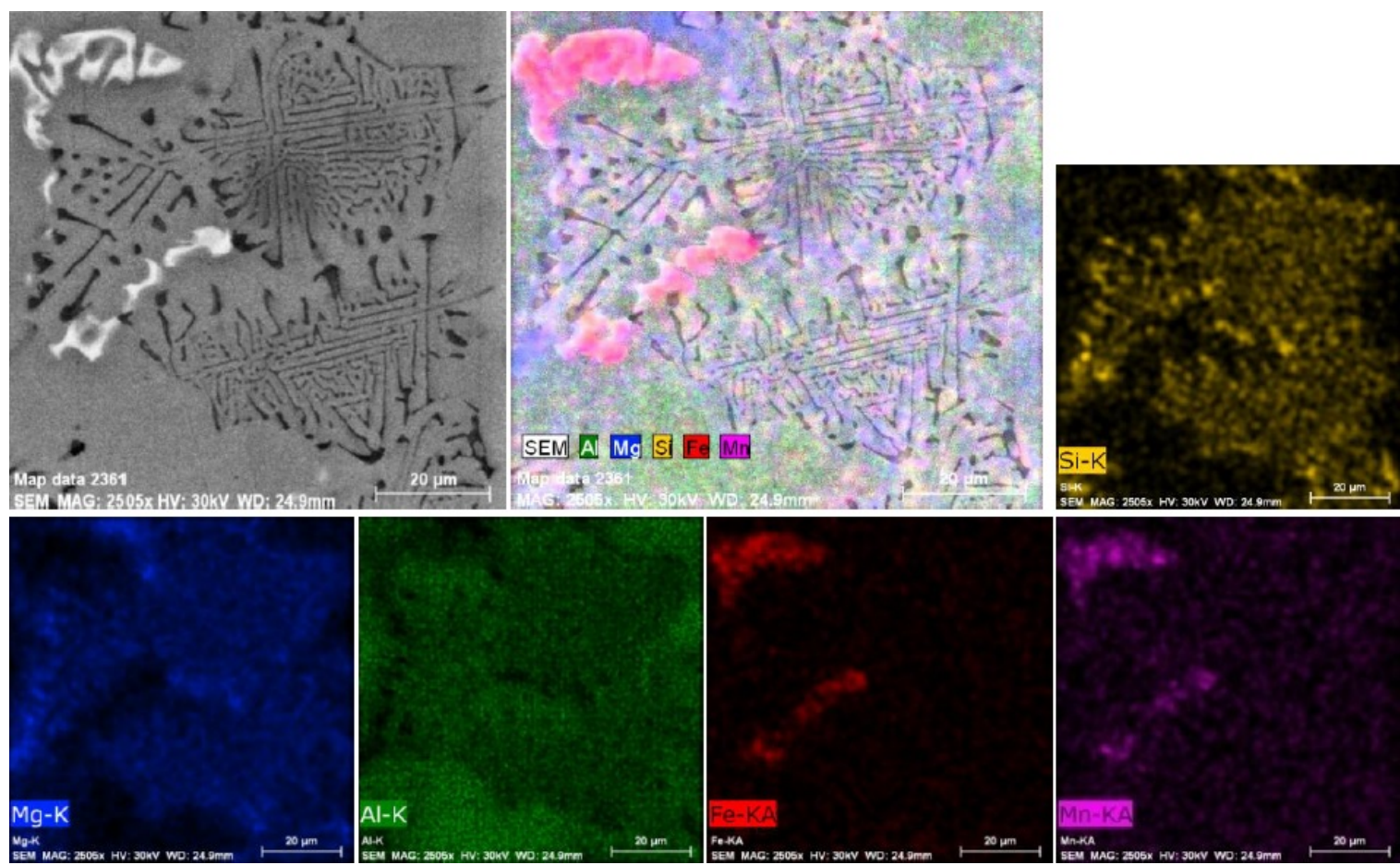

Fig. 7. Identification of structural components of aluminium alloy EN AC 51500 - a square analysis

It was also made a percentage assessment of shares of individual phases (Figs. 9,10). Results are shown in the Table 2. It can be concluded that the phase $\mathrm{Al}_{6}(\mathrm{FeMn})$ is comparable in both alloys. $\mathrm{Mg}_{2} \mathrm{Si}$ phase is about $4 \%$ higher in alloy EN AC 51500. This phase can improve the hardness and tensile strength, but can also aggravate the fracture toughness and the ductility, depending on the morphology and the amount. Only the alloy EN AC 51200 contained the $\beta$-phase, in an amount of $8 \%$. This phase is a brittle and reduced ductility at temperatures below $350^{\circ} \mathrm{C}$. 

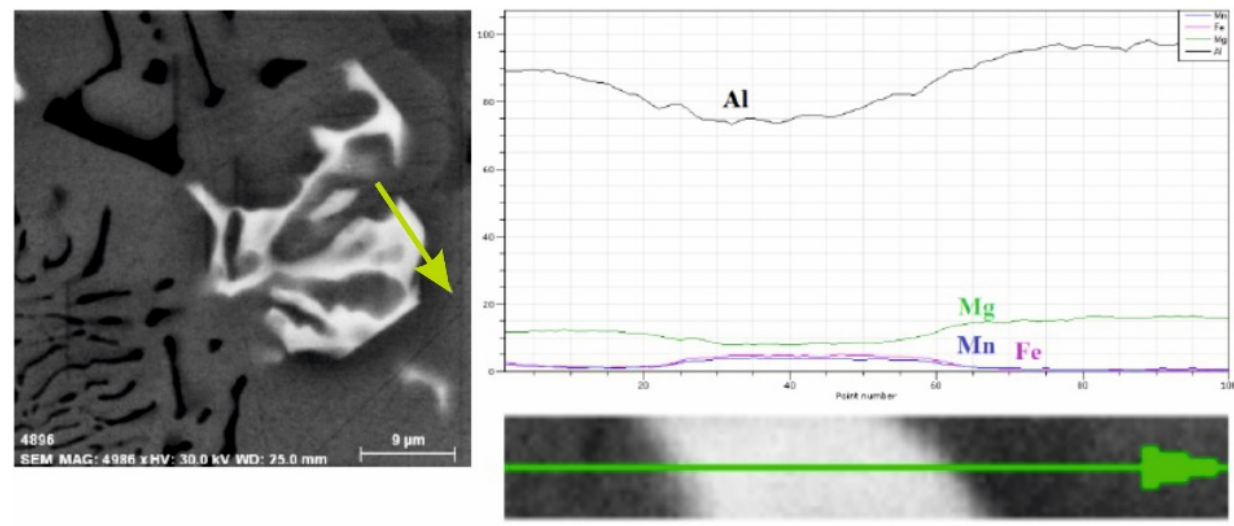

a) $\mathrm{Al}_{6}(\mathrm{FeMn})$
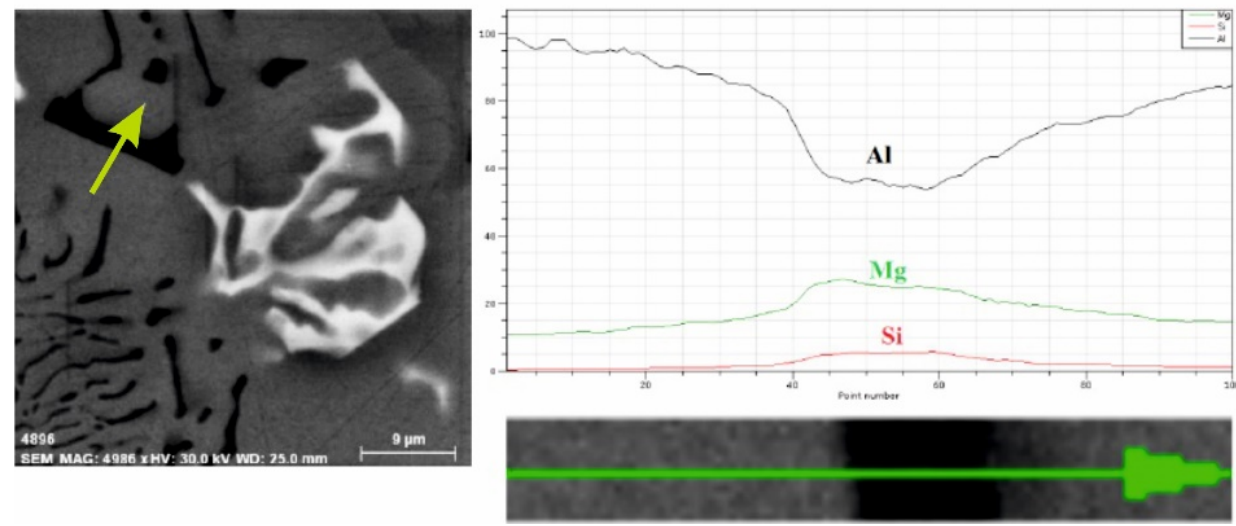

b) $\mathrm{Mg}_{2} \mathrm{Si}$

Fig. 8. Identification of structural components of aluminium alloy EN AC 51500 - a line analysis

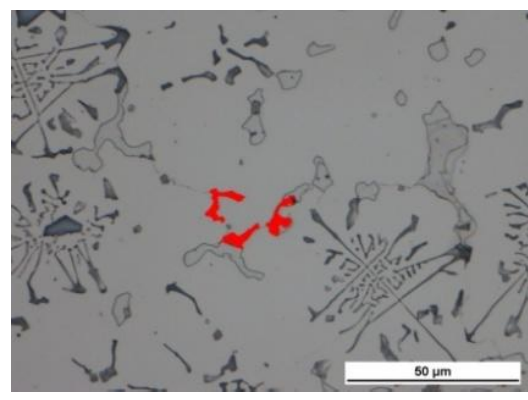

a) a share of $\mathrm{Al}_{6}(\mathrm{FeMn})$

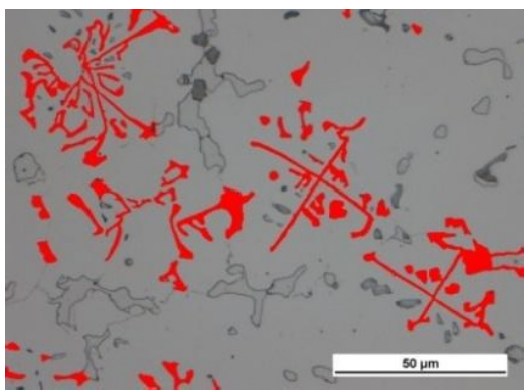

b) a share of $\mathrm{Mg}_{2} \mathrm{Si}$

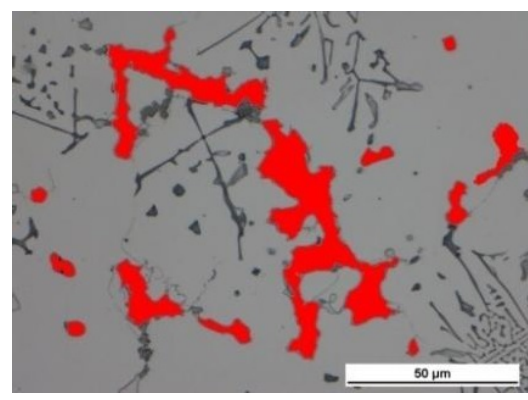

c) a share of $\mathrm{Al}_{3} \mathrm{Mg}_{2}$

Fig. 9. A measuring of percentage assessment of phases in the alloy EN AC 51200

TABLE 2

A percentage assessment of phases in alloys [\%]

\begin{tabular}{|l|c|c|c|c|}
\hline & $\mathbf{A l}_{3} \mathbf{M g}_{2}$ & $\mathbf{M g}_{2} \mathbf{S i}$ & $\mathbf{A l}_{\mathbf{6}}(\mathbf{F e M n})$ & $\boldsymbol{\alpha}$-phase \\
\hline EN AC 51200 & 8 & 7 & 0.7 & balance \\
\hline EN AC 51500 & 0 & 11 & 1.2 & balance \\
\hline
\end{tabular}

\subsection{Fatigue lifetime}

Alloys EN AC 51200 and EN AC 51500 were loaded by cyclic three-point bending loading with the same parameters, only stress amplitude was changing. From results of fatigue tests were constructed graphs $\sigma_{a}-N$ in semi-logarithmic coordinates, for every alloy (Figs. 11,12). By comparing of graphs can be stated that alloy EN AC 51500 has better fatigue properties than alloy EN AC 51200 in analyzed area of the number of cycles.

\subsection{Fractographic analysis}

Fracture surfaces of test specimens were evaluated at first in term of macrofractographic. From this analysis it is possible to determine initiation (nucleation) of fatigue crack, surfaces of individual areas of fracture, namely the fatigue fracture area and the area of static final failure.

A general view of the fracture area for the alloy EN AC 51500 after 1314148 cycles at a stress of $120 \mathrm{MPa}$ it documented in Fig. 13a, where can be seen various stages of fatigue process. Detail of initiation site is shown in Fig. 13b. Transgranular fa- 


\section{PAN}

1620

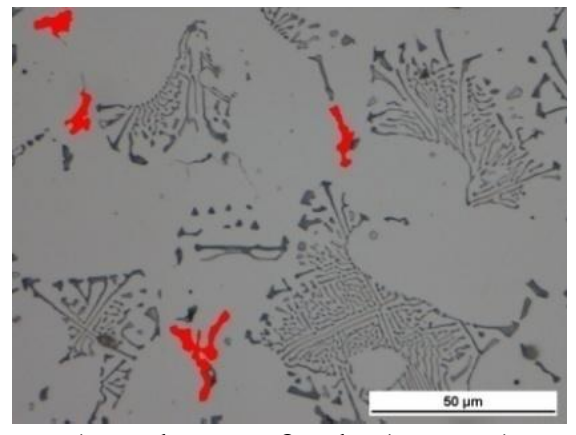

a) a share of $\mathrm{Al}_{6}(\mathrm{FeMn})$

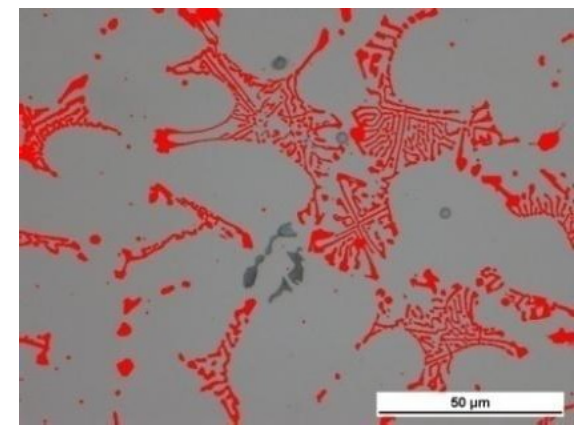

b) a share of $\mathrm{Mg}_{2} \mathrm{Si}$

Fig. 10. A measuring of percentage assessment of phases in the alloy EN AC 51500

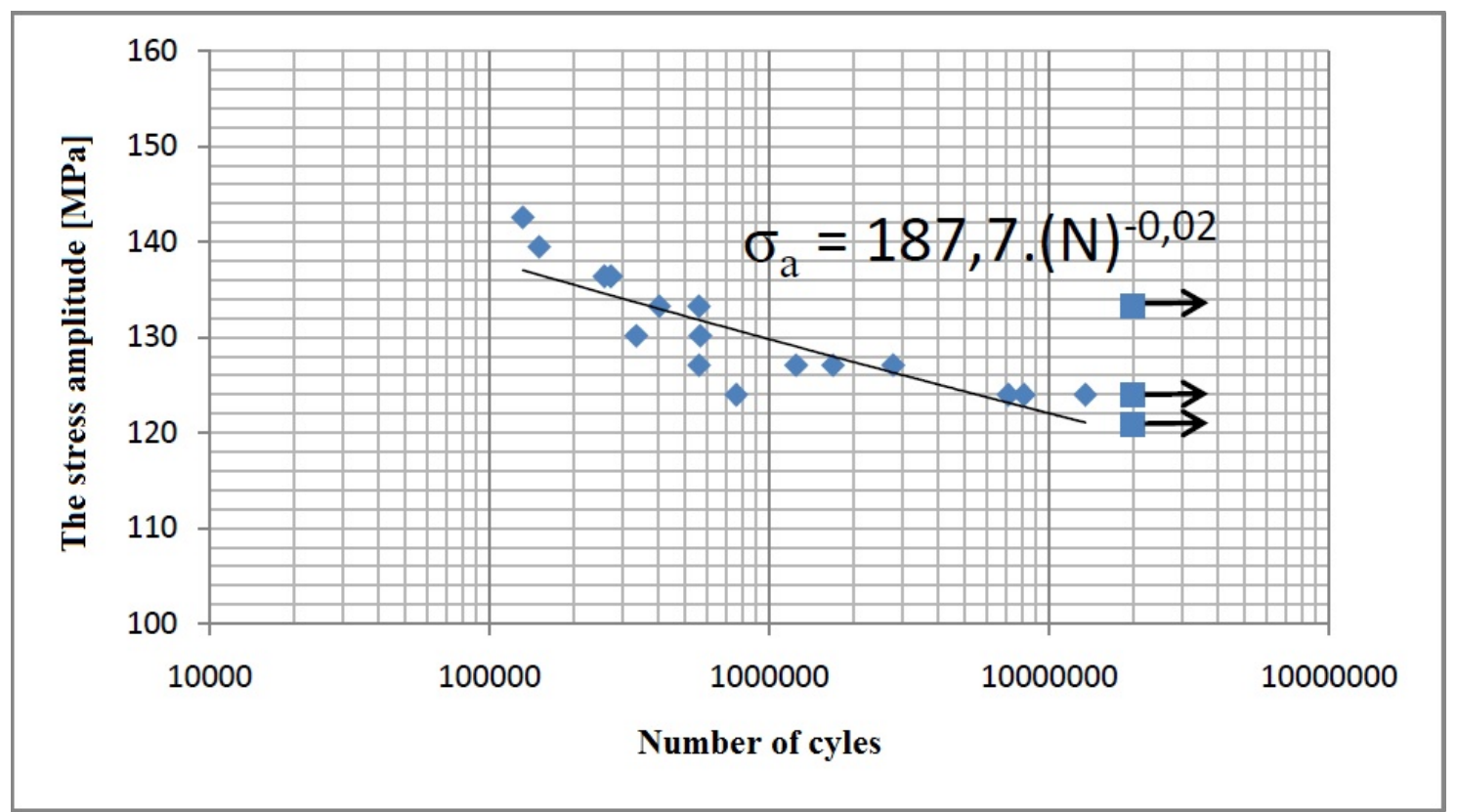

Fig. 11. Results of fatigue tests for alloy EN AC 51200

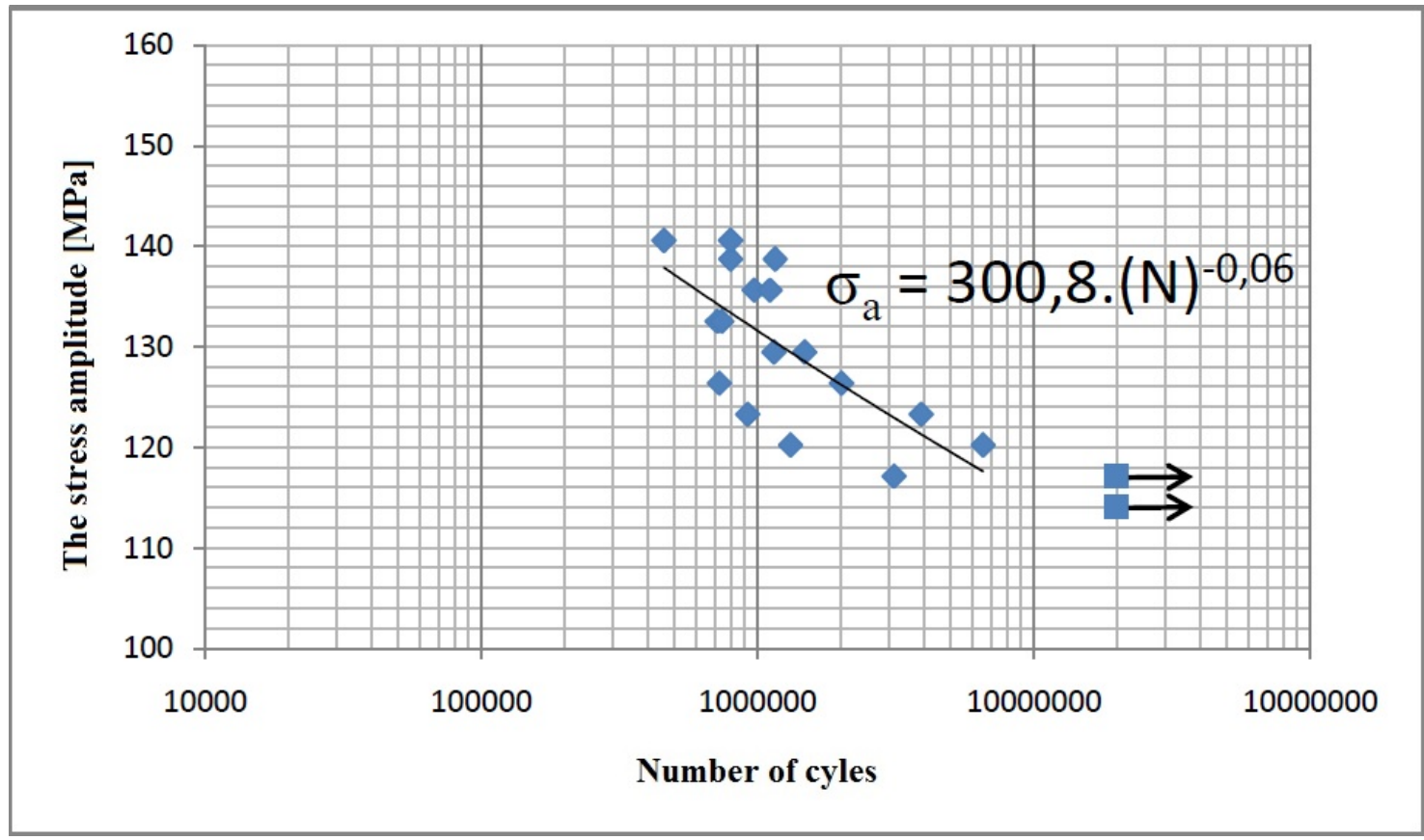

Fig. 12. Results of fatigue tests for alloy EN AC 51500 


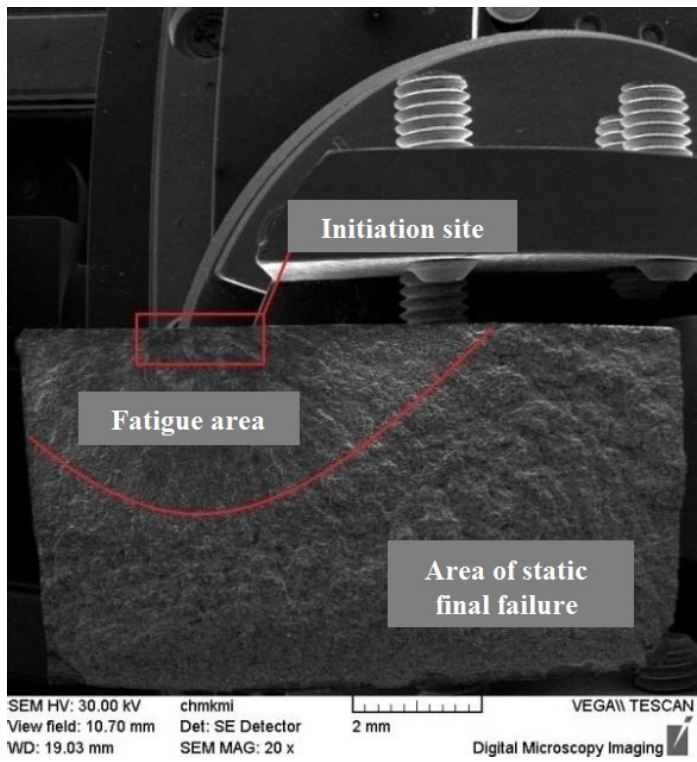

a) a general view

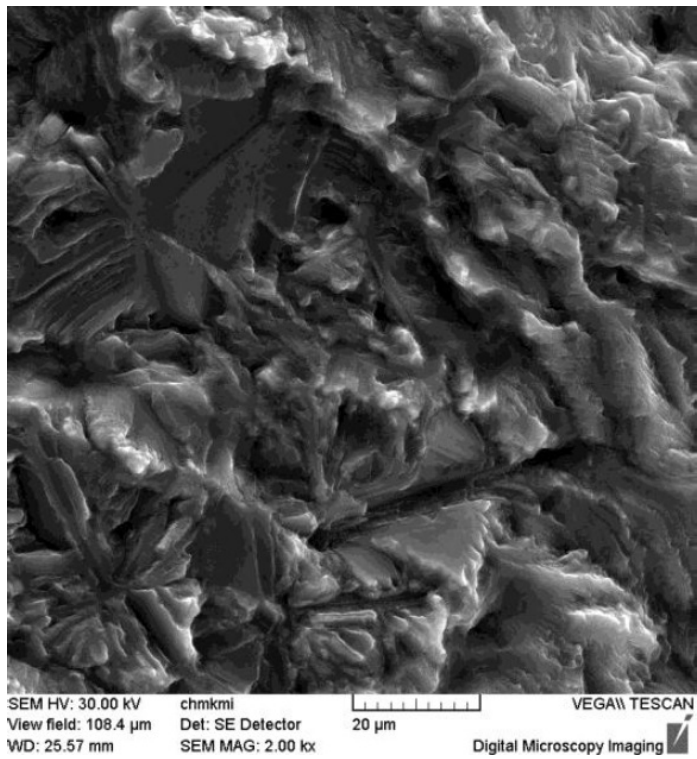

c) a detail from the fatigue area

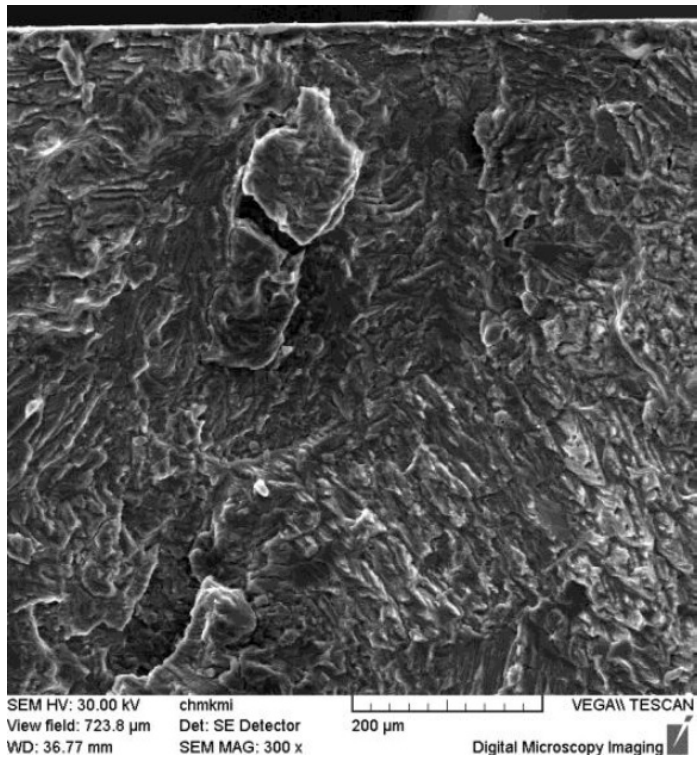

b) a detail of initiation site

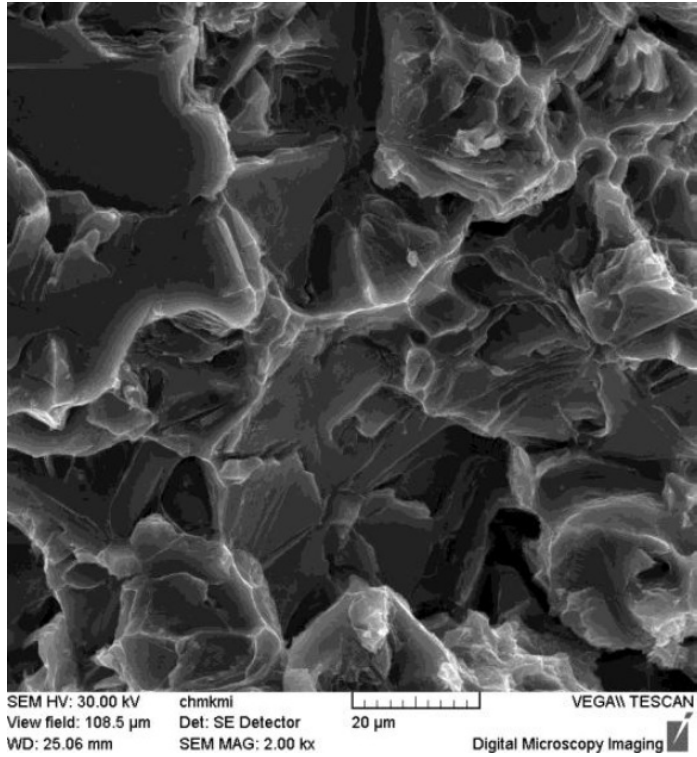

d) a detail from the area of static final failure

Fig. 13. Fracture surface of aluminium alloy $51500, \sigma_{a}=120 \mathrm{MPa}, N_{f}=1314148$ cycles

tigue failure of $\alpha$-phase (matrix) and there were observed typical signs of fatigue - striations and also an interfacial and a fission failure of $\mathrm{Mg}_{2} \mathrm{Si}$ phase, this all is shown in (Fig. 13c,d) displays the area of static final failure, where can be seen plastic's transformed ridges of $\alpha$-phase, together with a transgranular ductile fracture of $\alpha$-phase with dimple morphology and also is visible an interfacial failure of $\mathrm{Mg}_{2} \mathrm{Si}$ phase.

A general view of the fracture area for the alloy EN AC 51500 after 799229 cycles at a stress of $138 \mathrm{MPa}$ is shown in Fig. 14a. Here can be seen that when higher amplitude of stress was applicate, the fatigue crack was spread from several initiation sites on the specimen surface and there was also a reduction of the fatigue area. Detail of one initiation site is shown in Fig. 14b. Transgranular fatigue failure of $\alpha$-phase (matrix) and there were observed typical signs of fatigue - striations a it is shown in (Fig 14c,d) displays the area of static final failure, where can be also seen plastic's transformed ridges of $\alpha$-phase, together with transgranular ductile fracture of $\alpha$-phase with dimple morphology and also is visible an interfacial failure of $\mathrm{Mg}_{2} \mathrm{Si}$ phase.

A general view of the fracture area for the alloy EN AC 51200 after 761899 cycles at a stress of $124 \mathrm{MPa}$ is documented in Fig. 15a, where can be seen various stages of fatigue process. Detail of initiation site is shown in Fig. 15b. In Fig 15c can be seen an interfacial failure of intermetallic phases $\left(\mathrm{Al}_{3} \mathrm{Mg}_{2}\right.$, $\mathrm{Al}_{6}(\mathrm{FeMn})$ and $\left.\mathrm{Mg}_{2} \mathrm{Si}\right)$ and also a transgranular fatigue failure of $\alpha$-phase (matrix). Fig. 15d displays the area of static final failure, where can be seen interfacially broken intermetallic phases and plastic's transformed ridges of $\alpha$-phase, together with transgranular ductile fracture of $\alpha$-phase with dimple morphology. 


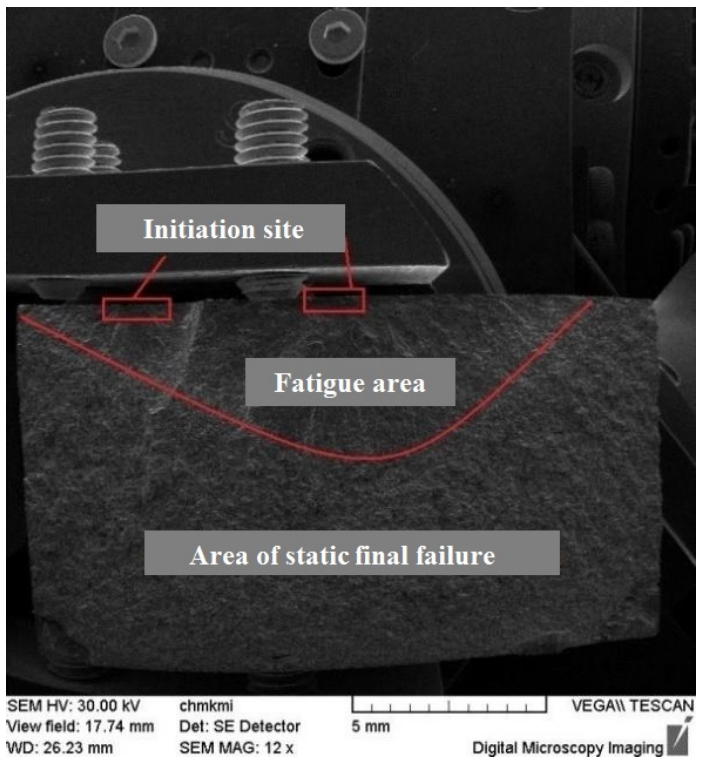

a) a general view

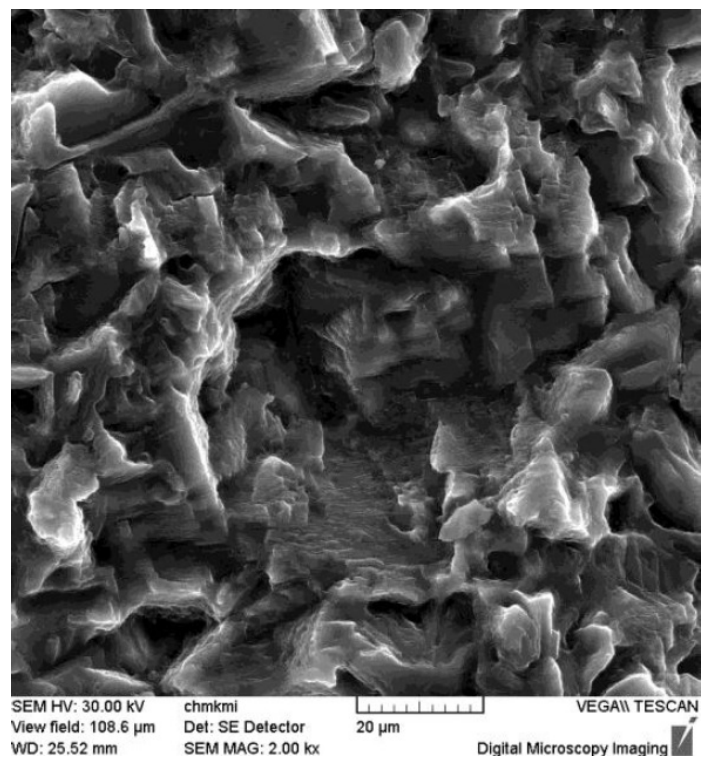

c) a detail from the fatigue area

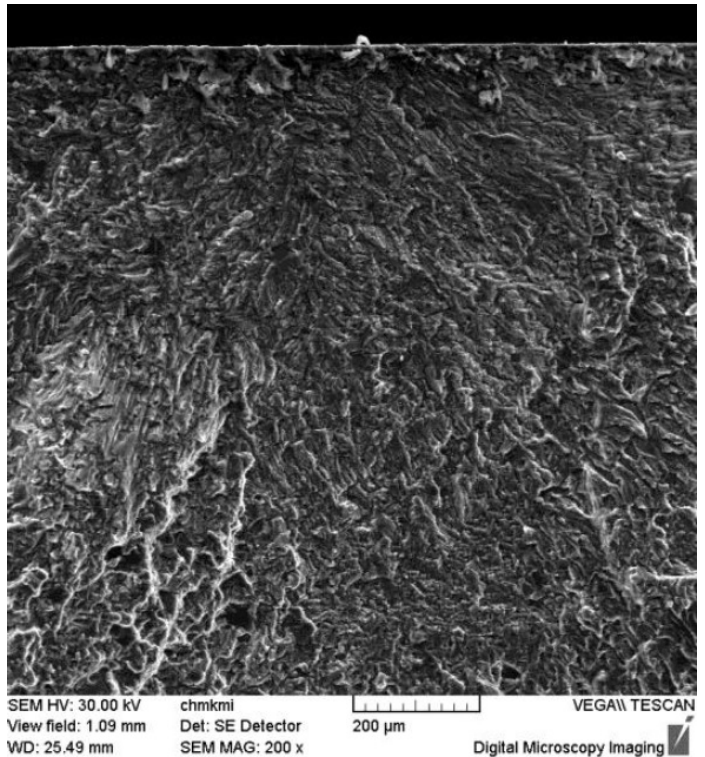

b) a detail of initiation site

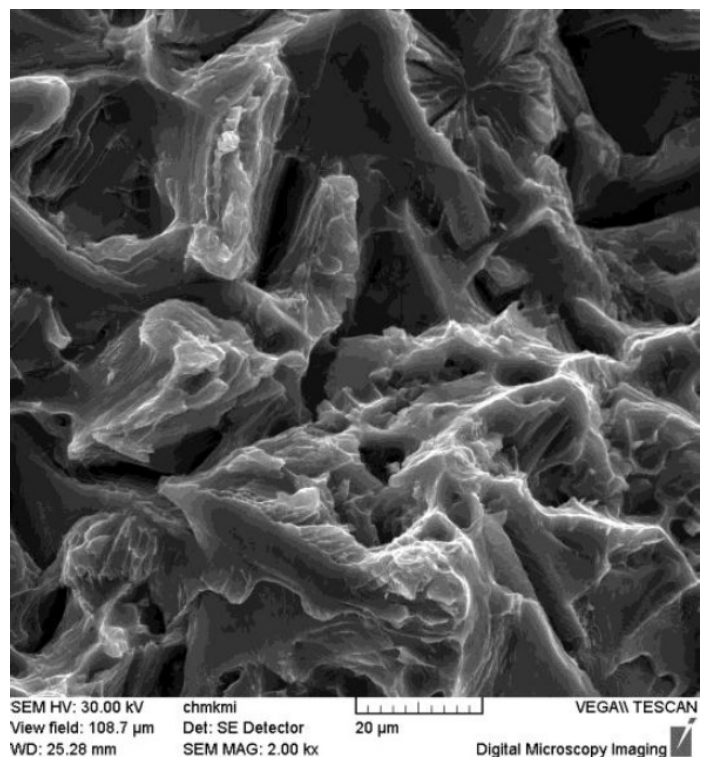

d) a detail from the area of static final failure

Fig. 14. Fracture surface of aluminium alloy $51500, \sigma_{a}=138 \mathrm{MPa}, N_{f}=799229$ cycles

A general view of the fracture area for the alloy EN AC 51200 after 150530 cycles at a stress of $139 \mathrm{MPa}$ is shown in Fig. 16a. Here can be seen that when higher amplitude of stress was applicate, the fatigue crack was spread from several initiation sites on the specimen surface and there was also a reduction of the fatigue area and a smaller number of cycles to fracture. Detail of one initiation site is shown in Fig. 16b. In Fig 16c can be seen a transgranular fatigue failure of $\alpha$-phase (matrix) and also an interfacial failure of intermetallic phases $\left(\mathrm{Al}_{3} \mathrm{Mg}_{2}\right.$ and $\left.\mathrm{Al}_{6}(\mathrm{FeMn})\right)$. Fig. 16d displays the area of static final failure, where can be seen plastic's transformed ridges of $\alpha$-phase, together with a transgranular ductile fracture of $\alpha$-phase with dimple morphology and also is visible an interfacial failure of $\mathrm{Mg}_{2} \mathrm{Si}$ and $\mathrm{Al}_{3} \mathrm{Mg}_{2}$ phases.

\section{Conclusion}

On the basis of performed experimental fatigue tests can be drawn following conclusions:

- $\quad$ Square and line analysis showed, what elements and phases are found in selected alloys.

- Alloys have a clearly dendritic structure consisting mainly $\alpha$-phase. In the structure of both alloys are intermetallic $\mathrm{Al}_{6}(\mathrm{FeMn})$ and $\mathrm{Mg}_{2} \mathrm{Si}$ phases. In alloy EN AC 51200, there is also an intermetallic $\mathrm{Al}_{3} \mathrm{Mg}_{2}$ phase.

- Alloys are different in terms of morphology and amount of intermetallic $\mathrm{Mg}_{2} \mathrm{Si}$ phase. The alloy EN AC 51200 has this phase in a shape of skeleton formation in the amount of $7 \%$. 


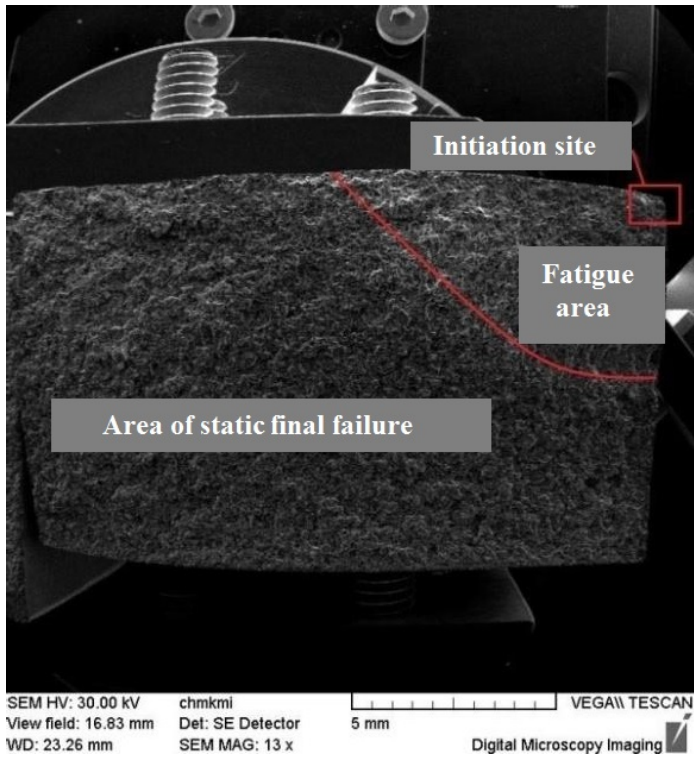

a) a general view

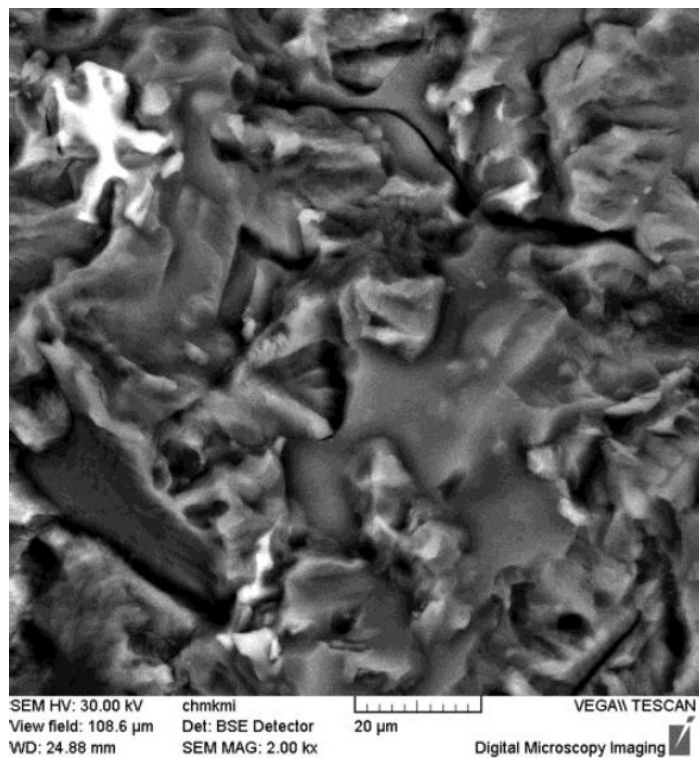

c) a detail from the fatigue area

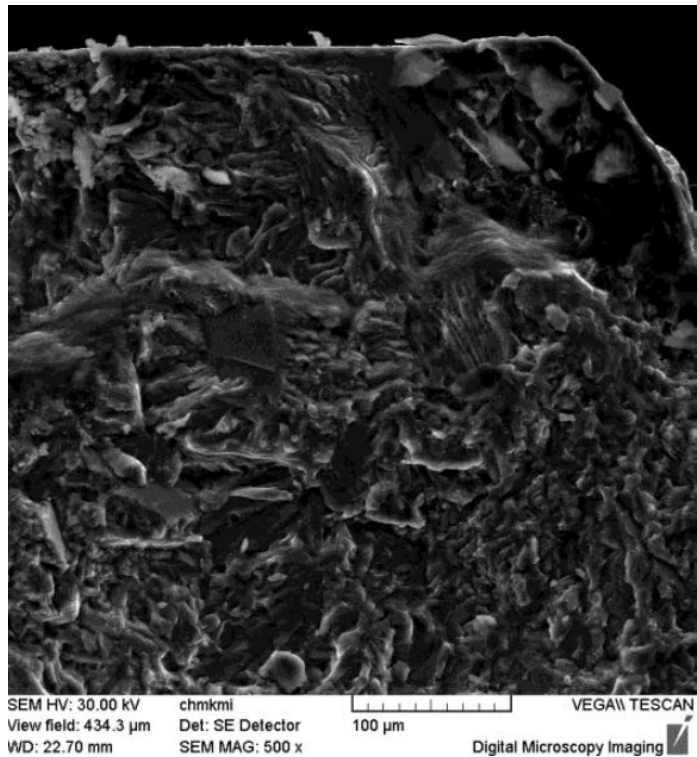

b) a detail of initiation site

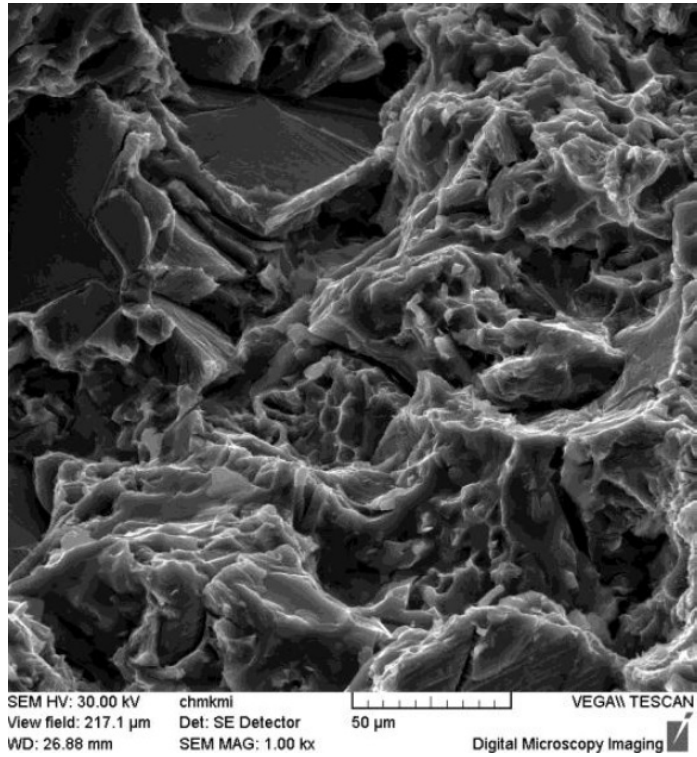

d) a detail from the area of static final failure

Fig. 15. Fracture surface of aluminium alloy $51200, \sigma_{a}=124 \mathrm{MPa}, N_{f}=761899$ cycles

In the case of alloy EN AC 51500 is a finer morphology of this phase and the percentage is $11 \%$.

- Alloys are comparable in terms of morphology and the amount of $\mathrm{Al}_{6}(\mathrm{FeMn})$ phase.

- $\quad$ From fatigue tests, it can conclude that alloy EN AC 51500 has better fatigue properties than alloy EN AC 51200, in the analyzed areas of number of cycles under the same conditions of loading.

- Fraktographic analysis did not reveal significant changes of micromechanisms of fracture surfaces after fatigue tests. Fatigue area is characterized by transgranular fatigue failure of $\alpha$-phase (matrix). Intermetallic phases in this area were violated interfacially, only $\mathrm{Mg}_{2} \mathrm{Si}$ phase had also a fission failure somewhere. The area of static final failure is typical of a transgranular ductile fracture of $\alpha$-phase with dimple morphology with plastic's transformed ridges. When comparing both of alloys, it can be stated that the only difference is that on the fracture surface of alloy EN AC 51500 is not an interfacially broken $\mathrm{Al}_{3} \mathrm{Mg}_{2}$ phase, because this alloy does not contain it.

- In terms of stress amplitude can be said that in case of a higher amplitude of cyclic loading there was a multiple initiation of fatigue crack.

- From the analysis of the influence of the structure on the fatigue properties, it can be stated that the alloy EN AC 51500 has better fatigue properties due to a smaller amount of intermetallic phases, which are finer. 


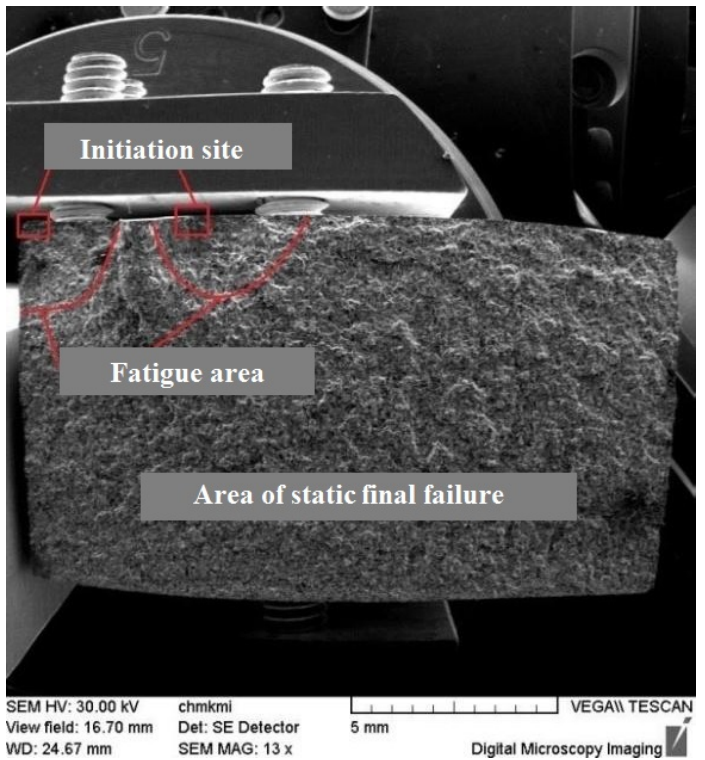

a) a general view

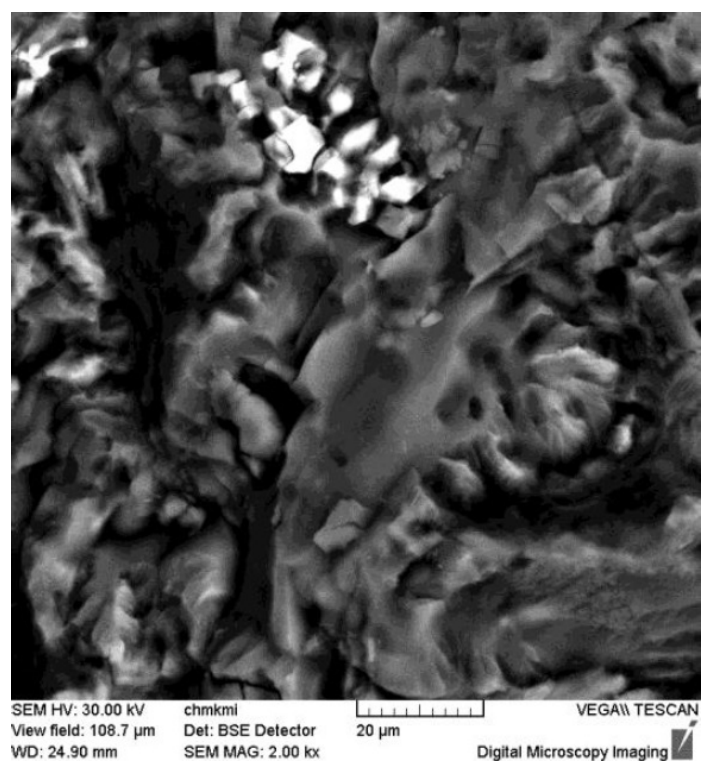

c) a detail from the fatigue area

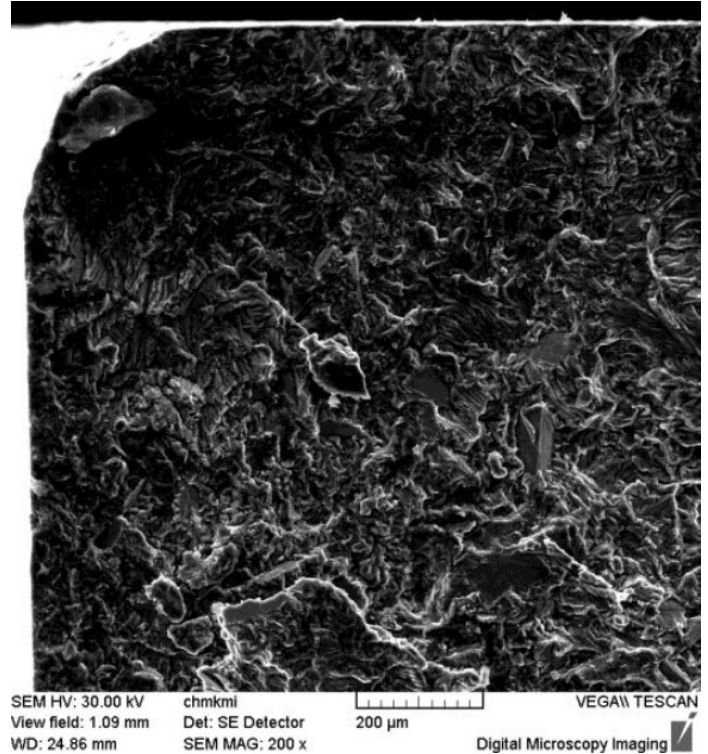

b) a detail of initiation site

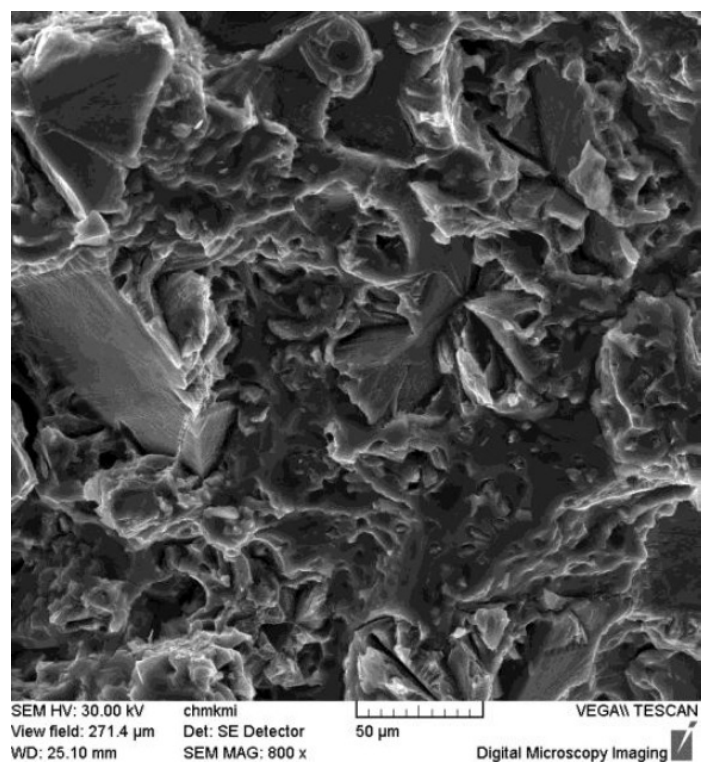

d) a detail from the area of static final failure

Fig. 16. Fracture surface of aluminium alloy $51200, \sigma_{a}=139 \mathrm{MPa}, N_{f}=150530$ cycles

\section{Acknowledgement}

This work has been supported by Scientific Grant Agency of Ministry of Education of Slovak republic, $\mathrm{N}^{\circ} 1 / 0683 / 15$ and $\mathrm{N}^{\circ} 1 / 0533 / 15$.

\section{REFERENCES}

[1] I.J. Polmear, Light alloys-metallurgy of the light metals, London 1995.

[2] L. Hurtalová, E. Tillová, Manufacturing Technology 13 (1), 44-50 (2013).
[3] ASM metals handbook, properties and selection: nonferrous alloys and special-purpose materials, Ohio, USA 1990.

[4] S. Lathabai, P.G. Lloyd, Acta Materialia 50 (17), 4275-4292 (2002).

[5] V. Zatkalíková, L. Markovičová, J. Belan, T. Liptáková, Manufacturing Technology 14 (3), 493-497 (2014).

[6] B. Hussey, J. Wilson, Light alloys, London 1998.

[7] J. Belan, L. Hurtalová, A. Vaško, E. Tillová, Manufacturing Technology 14 (3), 262-267 (2014).

[8] F. Nový, V. Zatkalíková, O. Bokůvka, K. Miková, Periodica Polytechna: transportation engineering 41 (2), 99-103 (2013).

[9] C. Bathias, Fatigue in the very high cycle regime, Vienna, Austria 2001. 